\title{
PERFIS DOS CONTROLLERS: AUTONOMIA E ENVOLVIMENTO DOS PROFISSIONAIS DE CONTROLADORIA
}

\author{
Gustavo Henrique Costa Souza' \\ Cláudio de Araújo Wanderley²
}

Kate Horton ${ }^{3}$

\section{Resumo:}

Objetivo: Partindo de dois perfis específicos (bean counters e business partners), o estudo possui três objetivos: primeiro, identificar quais as principais atividades desempenhadas por controllers atuantes no Brasil; segundo, discernir qual destes perfis destacados é predominante; e terceiro, identificar se a autonomia e o envolvimento dos controllers estão associados ao tamanho e à descentralização da organização em que atuam.

Método: A coleta de dados se deu por meio da aplicação de um questionário, o qual foi remetido por e-mail aos controllers membros da Associação Nacional dos Executivos de Finanças (ANEFAC).

Resultados: Foram validamente respondidos 111 questionários (taxa de resposta de 18,62\%), os quais evidenciaram que entre as atividades dos controllers predominam: análise de relatórios financeiros, controle de desempenho gerencial, escrituração e monitoramento fiscal - apontando para uma prevalência do perfil bean counter ( $74,5 \%$ da amostra). A descentralização também se mostrou positiva e significante tanto em relação à autonomia quanto em relação ao envolvimento.

Contribuição: A identificação da descentralização como um fator organizacional associado à autonomia e envolvimento dos controllers contribui com o entendimento acerca dos direcionadores da atuação destes profissionais. A identificação de suas tarefas e a caracterização do seu perfil oferecem um pano de fundo para investigações futuras sobre o processo de redefinição de papéis e atribuições dos controllers.

Palavras-chave: Controller; Controladoria; Contabilidade Gerencial; Envolvimento; Autonomia.

\footnotetext{
'guga.hcs@gmail.com. Universidade Federal de Pernambuco, Recife-PE. Brasil. https://orcid.org/0000-0003-1536-1629

2claudio.wanderley@ufpe.br. Universidade Federal de Pernambuco, Recife-PE. Brasil. Brasil. https://orcid.org/0000-0002-4559-176X

${ }^{3}$ khorton@rsm.nl. Universidade Federal de Pernambuco, Recife-PE. Brasil. Brasil. https://orcid.org/0000-0002-5542-0569

- DOI: http://dx.doi.org/10.14392/asaa.2020130301

- Artigo submetido em: 16/04/2020. Revisões requeridas em: 16/06/2020. Aceito em: 20/08/2020.
} 


\title{
CONTROLLERS' PROFILES: AUTONOMY AND INVOLVEMENT IN THE MANAGEMENT ACCOUNTING PROFESSION
}

\begin{abstract}
:
Objective: Focusing on two specific controllers' profiles (bean counters and business partners), the study has three objectives: first, to identify the main activities carried out by Brazilian controllers; second, to discern which of these highlighted profiles is predominant in the Brazilian context; and third, to identify whether the autonomy and involvement of the controllers is associated with the size and level of decentralization of the organization.

Method: Data collection was based on a questionnaire survey. The questionnaires were sent by email to controllers who are members of the Brazilian Association of Finance Executives (ANEFAC).

Results: Our final sample consisted of 111 controllers/management accountants, which represented a response rate of $18,62 \%$. The responses showed that the main activities carried out by the controllers were: analysis of financial reports, performance management, bookkeeping, and fiscal monitoring, with a majority of accountants enacting the bean counter profile ( $74.5 \%$ of the sample). Our study also shows that the level of organizational decentralization was significantly (positively) associated with controllers' autonomy and business involvement.

Contribution: In general, our study contributes to further shed light on the relationship between important organizational factors (e.g. decentralization) and autonomy and business involvement in the management accounting profession. We believe that by identifying controllers' tasks and profiles, we can offer interesting future avenues for new investigations on the process of reshaping and reframing management accountants' roles and activities.
\end{abstract}

Keywords: Controller; Controllership; Management Accounting; Involvement; Autonomy. 


\section{INTRODUÇÃO}

A o delinear a estrutura de competências requerida dos controllers, o Chartered Global Management Accountant (CGMA) afirma, nos seus Princípios Globais, que tanto as habilidades técnicas (relacionadas a finanças, contabilidade e gerência de negócios) quanto as sociais (relacionadas à liderança e à capacidade de influenciar pessoas) são componentes importantes na formação destes profissionais.

Após apontar estes atributos, porém, o CGMA (2014, p. 14) reconhece que "o papel dos controllers está mudando", de modo que eles estão cada vez mais exercendo sua influência sobre as decisões da organização e gerando, com isto, mais impacto sobre o negócio. Isto sinaliza que, embora haja uma tentativa por parte do CGMA de definir um perfil específico para os controllers, o mercado tem uma dinâmica própria que está conduzindo estes profissionais a uma mudança de papéis com consequente transição de perfis. Assim, em um ambiente de modificações que clama e impõe a reconfiguração dos controllers, emerge o desejo e a oportunidade de explorar a essência desta profissão e do seu exercício.

Seis anos antes desta iniciativa do CGMA, Brewer $(2008$, p. 36) discutia uma redefinição da controladoria - que passava, necessariamente, por repensar o papel dos controllers dentro do que ele chamou de "uma nova estrutura". Segundo Brewer (2008, p. 36), a controladoria se assenta sobre quatro pilares, quais sejam: liderança, gestão estratégica, alinhamento operacional, melhoria e aprendizado contínuos; e, "em última instância, a responsabilidade dos controllers é gerar valor para os acionistas".

Esta perspectiva, aliás, destoa um pouco da estrutura proposta pelo Chartered Global Management Accountants, pois Brewer (2008) utiliza a expressão"geração de valor" ao passo que o CGMA (2014) adoto um termo mais abrangente: "geração de impacto". Outrossim, a dimensão de "melhoria e aprendizado contínuos" - presente em Brewer (2008) - não consta no material do CGMA (2014), embora seja razoável crer que ela é um componente natural e importante quando se pensa no processo de formação dos controllers. Assim, o que se percebe com estes paralelos é a existência de um movimento de aprimoramento conceitual: uns componentes são modificados, outros excluídos, e outros inseridos. Mas sempre na perspectiva de melhor definir um escopo para as funções, ainda controversas, do controller e da controladoria.

Retrocedendo um pouco mais, percebe-se que a International Federation of Accountants (IFAC) já segregava a atuação do controller em duas funções distintas: a função financeira e a gerencial. Sendo que a função financeira correspondia "às atividades contábeis e à preparação de demonstrações financeiras direcionadas a usuários externos"; e a função gerencial tinha o seu foco "em fornecer informação à gerência da organização para a tomada de decisões internas" (IFAC, 2005, p. 12). Esta visão bifuncional é, ainda hoje, um componente importante para que se compreenda a mudança nos papéis desempenhados pelos controllers.

Na sequência, após traçar uma perspectiva histórica da evolução da controladoria, o IFAC (2005, p. 13) afirmou que a tendência é um reposicionamento do papel dos controllers: eles têm passado "do acompanhamento de informações a papéis mais estratégicos ligados a planejamento e controle". Àquela época, determinadas áreas já requeriam do controller uma postura diferenciada: o Institute of Chartered Accountants in England and Wales (ICAEW), por exemplo, em um relatório intitulado Sustainability:The Role of Accountants, publicado em 2004, anunciou uma ampliação do papel dos contadores no que diz respeito ao "desenvolvimento da controladoria para uso nos relatórios internos de impactos sociais 
e ambientais, mensuração de performance, interpretação da informação e subsequente tomada de decisão" (ICAEW, 2004, p. 81).

Estas mudanças na controladoria têm sido percebidas e apontadas por diversos estudiosos (Friedman \& Lyne, 2001; Lambert \& Sponem, 2012; Vaivio \& Kokko, 2006). Estes estudiosos afirmam que elas impactam - naturalmente - naqueles que trabalham nesta área: tanto nas funções que desempenham, quanto nos perfis que adotam. Burns e Baldvinsdottir (2007, p. 117), por exemplo, asseveram que estas transformações consistem, sobretudo, em passar do "enfadonho e tedioso papel de registrador" ao "excitante e proativo papel de consultor de negócios". Youssef (2012, p. 1000), por sua vez, complementa destacando que a ênfase atual "está sendo colocada em papéis de estratégia e tomada de decisões, mais que nas áreas mais tradicionais de custeio e análise financeira".

Embora a literatura aponte neste sentido de transição e de um maior envolvimento do controller com o negócio e com a estratégia empresarial, há indícios de que este processo não é uniforme em todas as organizações, e nem sequer acontece em todas elas. Lambert e Sponem (2012), por exemplo, afirmam que não é tão comum encontrar controllers que atuem, efetivamente, como parceiros do negócio. Rahman e Ahmed (2012), por seu turno, relatam que a mudança que se tem verificado no papel do controller ocorre predominantemente em grandes empresas (com recursos abundantes para impulsionar esta dinâmica). As pequenas empresas, segundo estes autores, ainda resistem - por razões diversas - a instigar e instrumentalizar este tipo de modificação.

A literatura acadêmica enfatiza, ainda, que os indivíduos podem adotar uma postura mais tradicional (que na língua inglesa é identificada pela expressão bean counters), a qual - tipicamente - está associada às atividades de registro e acumulação de dados, elaboração de demonstrações financeiras, análise, controle e fiscalização da performance dos gestores operacionais por meio do uso de indicadores financeiros (Burns \& Baldvinsdottir, 2005, Emsley, 2005); ou uma postura mais orientada para estratégia, a qual usualmente está ligada a um alto nível de envolvimento com o negócio e um alto grau de cooperação com outras funções da empresa com o objetivo de integrar informações contábeis com indicadores financeiros (Burns \& Baldvinsdottir, 2005). Neste caso, os controllers são chamados de business partners.

Embora já algum tempo pesquisas internacionais (Byrne \& Pierce, 2007; Gibson, 2002; Siegel \& Sorensen, 1999) apontem para uma modificação do papel do controller marcada por uma transição do bean counter para o business partner, ainda se faz necessário depreender o modo como determinados fatores (externos e internos) se relacionam com essa transição da profissão, e - ainda mais especificamente - como ela se dá em países em desenvolvimento, como o Brasil.

A literatura nacional (Palomino, 2013, Cardoso, Mendonça Neto, \& Oyadomari, 2010, Lunkes, Gasparetto, \& Schnorrenberger, 2010), na esteira de estudos internacionais (Lambert \& Sponem, 2012; Verstegen, De Loo, Mol, Slagter, \& Geerkens, 2007), tem apontado para um paradoxo entre o perfil de controller que a academia e as associações de classe apresentam e a práxis cotidiana nas organizações: embora sejam classificados com business partners, os controllers continuam a executar atividades próprias dos bean counters.

Estudos nacionais também relatam as exigências do mercado quanto ao perfil profissional do controller (Calijuri, 2004; Duque, 2011; Ferrari, Cunha, Lunkes, \& Borgert, 2013). Mas não arrematam sobre se estas exigências têm sido satisfeitas, isto é, se o perfil que o mercado espera é, de fato, o que os controllers demonstram. Tampouco se sabe que/quais características destas organizações poderiam impactar ou mesmo moldar este perfil. Tais contradições e lacunas endossam a necessidade de estudos sobre o assunto e justificam a realização da presente pesquisa aplicada ao contexto brasileiro. 
Assim, uma vez expostas as razões da problemática, esta pesquisa busca responder ao seguinte questionamento: De que forma o tamanho e o grau de descentralização das organizações estão associados com o envolvimento e autonomia (características associadas ao perfil business partner) dos Controllers?

\section{CARACTERIZAÇÃO DO CONTROLLER}

No contexto da profissão contábil, o termo "perfil foi definido como um "conjunto de habilidades, maneiras de agir e atuar de um profissional em um determinado contexto" (Nogueira \& Fari, 2007, p. 118119). Partir desta noção é importante para que se possa avançar na identificação dos perfis de controller que serão apresentados neste estudo.

A este respeito, Byrne e Pierce (2007) empreenderam uma consolidação na qual foram identificadas uma série de competências individuais e de atividades relacionadas ao perfil e à atuação do controller (ver Tabela 1).

Tabela 1 - Competências e atividades do controller

\begin{tabular}{|c|c|}
\hline Competências Individuais & Atividades \\
\hline Conhecimento do negócio & Fornecer e interpretar informação \\
\hline Habilidades interpessoais e comunicacionais & Apoiar decisões \\
\hline Habilidade com tecnologia da informação & Relatar e planejar informações periódicas \\
\hline Flexibilidade & Elaborar projetos \\
\hline Qualidades pessoais & Administrar \\
\hline Habilidades técnicas & Usar técnicas \\
\hline Capacidade de monitoramento & Instruir gerentes de operações \\
\hline Influência na organização & \\
\hline
\end{tabular}

Fonte: adaptada de Byrne e Pierce (2007, p. 488).

A partir da identificação destas competências e as atividades se pode estabelecer perfis de controller. Note-se que o uso aqui sempre será da palavra perfil: O emprego do termo identidade foi evitado em consideração à complexidade deste conceito - amplamente estudado na psicologia: trabalhar com este elemento seria desviar os propósitos deste estudo. Pela mesma razão, as expressões (auto)imagem, (auto) percepção foram evitadas no presente texto. Em lugar disso, optou-se por utilizar a expressão perfil, cujo sentido foi definido no início desta seção.

Assim, partindo da análise da literatura internacional disponível, é possível relacionar uma série de perfis associados ao controller (ver Tabela 2). Alguns se assemelham bastante, outros soam um tanto quanto pejorativos, e outros ainda são tão genéricos que poderiam ser aplicados, sem prejuízo de sentido nem confusão de funções, a diversos profissionais que atuam na organização - e não apenas aos controllers. 
Tabela 2 - Perfis dos controllers segundo a literatura internacional

\begin{tabular}{|c|c|c|}
\hline Perfil & Referências & Característica Predominante \\
\hline Bookkeeper & $\begin{array}{l}\text { Hopper (1980), Lambert e Sponem (2012), Rahman e Ahmed } \\
\text { (2012) e Sathe (1984) }\end{array}$ & Manutenção dos registros contábeis \\
\hline Business consultant & Burns e Baldvinsdottir $(2005,2007)$ & Assessoria a gestores \\
\hline Decision making facilitator & Lambert e Sponem (2012) & Habilidade com negociações \\
\hline Hybrid accountant & Burns e Baldvinsdottir (2007) e Burns e Scapens (2000) & Execução de atividades operacionais e financeiros \\
\hline Moderator & Ahrens e Chapman (2000) & Mediação entre gestores operacionais e financeiros \\
\hline Scorekeeper & Burns e Baldvinsdottir (2007) & Capacidade de avaliar desempenho \\
\hline Strategic management consultant & Holtzman (2004) & $\begin{array}{l}\text { Apoio à formulação e execução do planejamento } \\
\text { estratégico }\end{array}$ \\
\hline Corporate policeman & Byrne (2010) & $\begin{array}{c}\text { Supervisão e administração de regras e } \\
\text { procedimentos }\end{array}$ \\
\hline
\end{tabular}

A este respeito, aliás, é interessante destacar que alguns autores realizaram comparações entre perfis de controller. Assim é que Hopper (1980) contrapõe o perfil que ele chama de bookkeeper a um outro por ele batizado service-aid, cuja descrição se assemelha à do decision-making facilitator. Também nesta linha comparativa, Burns e Baldvinsdottir (2005) comparam o papel de business consultant ao de scorekeeping.

Além destes, há outros autores que vão nomear de modo particular o perfil do controller: strategic partner (Ahid \& Augustine, 2012), internal business consultant (Burns \& Vaivio, 2001), e modern business-oriented accountant (Granlund \& Lukka, 1998) são exemplos disso. Houve até quem os chamasse de watchdogs (Abernethy \& Brownell, 1999; Järvenpää, 2007; Pierce \& O'dea, 2003; Rahman \& Ahmed, 2012).

Importante ressalvar que a presente pesquisa optou por não aprofundar as colocações destes autores por entender que suas concepções já estão representadas dentro de perfis relacionados na Tabela 2: 0 internal business consultant citado por Burns e Vaivio (2001), por exemplo, já está contemplado dentro do conceito business consultant; o modern business-oriented accountant, de Granlund e Lukka (1998), pode ser compreendido como equivalente ao decision making facilitator; e watchdog, citado por tantos autores, encontra-se espelhado no corporate policeman, de Byrne (2010).

Burns e Scapens (2000), por sua vez, identificaram um perfil muito peculiar de controller, os chamados hybrid accountants. Mais tarde, Burns e Baldvinsdottir (2005) explicaram tratar-se de um perfil surgido a partir de 1995, momento em que - em algumas organizações multinacionais do ramo farmacêutico - os controllers foram alocados junto à linha de produção. Eles eram vistos como pessoas-chave para impulsionar as mudanças naquela área e também como a representação de uma autoridade capaz de ajudar a manter a estrutura de funcionamento da empresa em linha com sua estratégia.

Estes "contadores híbridos" foram didaticamente divididos em dois grupos: o dos gestores financeiros híbridos e o dos analistas financeiros híbridos (Burns \& Baldsvindottir, 2005, p. 739). Esta distinção, por si, já sinaliza uma segregação entre aqueles que efetivamente atuam sobre o processo de tomada de decisões e aqueles que apenas produzem a analisam informações. Os primeiros têm mais ligação com a estratégia do negócio, e os últimos estão mais ligados a um papel de mensuração, conferência e acompanhamento. Burns e Baldvinsdottir (2007, p. 177) descreveram o surgimento e a atuação de "contadores híbridos - que aconselhavam os líderes da produção em questões estratégicas, bem como auxiliavam outros gestores com decisões do dia a dia e medição de desempenho".

A afinidade entre os diferentes perfis se dá pelo tipo de atividade que desempenham dentro da organização. As atividades ligadas a suporte estratégico, consultoria e tomada de decisões, por exemplo, são usualmente associadas ao papel dos business partners; ao passo que as atividades ligadas a 
registro e conformidade procedimental costumam se alinhar mais ao papel dos bean counters. Portanto, embora a literatura elenque e nomeie uma plêiade de perfis, eles podem ser agrupados nestes dois grandes grupos (bussiness partners e bean counters) com base na descrição que a literatura faz das suas atividades. A Tabela 3 apresenta o lastro teórico que permitiu, por similaridade das atividades, realizar o agrupamento dos perfis.

Tabela 3 - Agrupamento de perfis dos controllers

\begin{tabular}{c|c|c} 
Grupo & Referências & Perfis Abrangidos \\
Bean Counters & $\begin{array}{c}\text { Burns e Baldvinsdottir (2005, 2007), Byrne e Pierce (2007), De } \\
\text { Lo, Verstegen e Swargerman (2011), Gibson (2002), Granlund e } \\
\text { Lukka (1998), Lambert e Sponem (2012), Mistry, Sharma e Low } \\
\text { (2014), Sunarni (2013), Rahman e Ahmed (2012), Vaivio e Kokko } \\
\text { (2006) e Verstegen et al. (2007). }\end{array}$ & $\begin{array}{c}\text { Bookkeeper, scorekeeper, corporate policeman } \\
\text { Business partners } \\
\text { Burns e Baldvinsdottir (2005, 2007), De Loo et al. (2011), } \\
\text { Järvenpää (2007), Lambert e Sponem (2012), Mistry et al. } \\
\text { (2014), Siegel e Sorensen (1999) e Sunarni (2013). }\end{array}$ \\
Fonte: elaborada pelos autores. & $\begin{array}{c}\text { Decision making facilitator, business consultant, } \\
\text { strategic management consultant }\end{array}$
\end{tabular}

Os perfis hybrid accoutant e moderator não foram enquadrados em nenhum dos grupos por não apresentarem semelhanças com os demais perfis e por representarem tentativas de conciliação ou equilíbrio entre estes dois grupos (meios-termos).

No presente estudo, o foco dos questionamentos e análises está nos perfis bean counter e business partner. A este respeito, é oportuno observar o trabalho de Granlund e Lukka (1998), que sistematizaram sua análise para traçar com clareza quais as características do perfil bean counter. Järvenpää (2007), por sua vez, apresenta um perfil de controller focado nos negócios da empresa e não nos seus próprios processos e rotinas, ao qual chama de business partners.

Uma vez estabelecidos estes dois grupos (o dos bean counters e o dos business partners), foi possível - ainda na fase de pré-pesquisa - tipificar a atuação deles. E, em decorrência desta tipificação, foi possível compará-los. A Tabela 4 apresenta esta comparação:

\begin{tabular}{|c|c|}
\multicolumn{2}{|c|}{ Tabela 4 - Comparativo bean counters $x$ business partners } \\
Bean Counters & Business Partners \\
Mensuração de itens financeiros & Mensuração de itens não-financeiros \\
Registro de dados & Análise de informações \\
Foco em execução & Foco em planejamento \\
Indiferença perante outros departamentos \\
Fornecimento de relatórios aos gestores \\
Controle de processos
\end{tabular}

Esta dualidade representada por bean counters e business partners é que subsidia a argumentação deste estudo. A predominância de um ou outro perfil, juntamente com o seu grau de envolvimento e autonomia, é aqui o elemento caracterizador da atuação dos controllers.

\section{DESENVOLVIMENTO DAS HIPÓTESES}

3.1 Tamanho da organização

Pesquisas mostram que o tamanho de uma organização pode afetar o seu funcionamento sob diversos aspectos. Laforet (2008), por exemplo, relacionou este elemento à orientação estratégica da empresa, à sua capacidade de inovar e às suas diretrizes de marketing. Hamdan (2011), por sua vez, 
demonstrou que o tamanho da companhia é uma das variáveis que afeta o grau de conservadorismo na preparação dos relatórios financeiros. Outros tantos estudos - em administração, mas também em psicologia organizacional, e até mesmo em engenharia - poderiam ser mencionados para justificar que o componente tamanho da empresa provoca múltiplos efeitos: sobre os resultados da empresa, sobre a sua cultura, sobre o comportamento de seus funcionários e gestores etc. (Ahlgren \& Engel, 2011; Chen \& Taylor, 2012; Dayanti \& Prihatiningtias, 2013).

No que tange ao controller, especificamente, Oliveira (1998) atesta que o tamanho é uma variável capaz de afetar as funções e as atividades deste profissional, o que - por conseguinte - pode contribuir para a modificação ou redefinição do perfil do controller.

Corroborando este pensamento, Monteiro (2014, p. 32) refere que organizações de maior porte "estão associadas com maior diversidade de operações, formalização de procedimentos e especialização de funções". Além disso, estas organizações, em geral, talvez porque têm mais departamentos, apresentam ferramentas de controle mais aprimoradas e dão maior importância às questões orçamentárias.

Nesta perspectiva, Calijuri, Santos e Santos (2005) realizaram uma survey e obtiveram quarenta questionários respondidos por controllers de grandes e médias empresas (apenas dois trabalhavam em empresas consideradas pequenas). Os autores concluíram que os controllers estavam exercendo naquelas organizações um papel diferente e descreveram em seus achados que estavam se tornando "um legítimo parceiro nos negócios" (Calijuri et al., 2005, p. 10).

Do mesmo modo, Schnorrenberger, Ribeiro, Lunkes, \& Gasparetto (2007, p. 14), estudando o perfil do controller em empresas de médio e grande porte em Florianópolis constataram que, além de um conhecimento profundo de contabilidade, as duas habilidades mais frequentemente requeridas destes profissionais, e consideradas pelos respondentes daquele estudo como muito importantes, são "iniciativa" e "liderança". Tais competências não parecem se coadunar com o perfil bean counter - voltado para a satisfação de exigências técnicas e execução de procedimentos - mas apontam nitidamente para o perfil business partner, mais direcionado à ação estratégica proativa, à condução dos negócios e às habilidades com pessoas, como preconizado pelo CGMA (2014).

Estudos como estes fornecem indícios de que nas empresas maiores o controller tipo business partner é mais facilmente requisitado e encontrado. Porém, por se tratarem de recortes locais, feitos já há alguns anos, os resultados destes estudos não oferecem uma resposta sobre o perfil atual dos controllers, a nível nacional. Há trabalhos, porém, como o de Oro, Dittadi, Carpes e Benoit (2009) que mostram que, de acordo com o porte, as empresas demandam diferentes perfis de controller: as menores querem que o profissional de controladoria exerça um papel mais operacional, ao passo que as maiores requerem alguém mais voltado à esfera estratégica.

Ademais, Singer (2004) sugere que os avanços da tecnologia proporcionaram a reestruturação das empresas e afetaram, entre outras coisas, o seu tamanho. A consequência disso para cada organização, segundo o autor, é que "em vez de ser hierárquica e burocrática, passou a ser em rede, portanto, muito mais horizontal, e os operários ganharam autonomia e poder de decisão" (Singer, 2004, p. 14).

Assim, sabendo que o tamanho da organização é uma variável positivamente relacionada à sua orientação estratégica (Laforet, 2008); que os controllers estão se envolvendo cada vez mais com o negócio (Calijuri et al., 2005) - isto é: tornando-se business partners; e que o porte das empresas - reconfigurado a partir das mudanças tecnológicas - conferiu mais autonomia aos empregados (Singer, 2004), foi estabelecida a primeira hipótese deste estudo: 
H1: Controllers de empresas de maior porte apresentam mais envolvimento com o negócio e mais autonomia.

\subsection{Descentralização}

"A essência da descentralização é a autonomia aos gestores das unidades de negócios" (Pinto, 1997, p. 6). Este pensamento condensa e traduz com clareza o que vem a ser a descentralização (e, por analogia, a centralização). Há bastantes pesquisas sobre este assunto no tocante ao setor público (Guimarães, 2014; Motta \& Bresser-Pereira, 2004; Vieira, 2012). Em diversos estudo, o cerne da questão diz respeito a como construir o fluxo de um processo decisório: uns defendem uma administração centralizada, outros primam por um comando descentralizado.

Contudo, essa temática não se restringe à esfera governamental: onde quer que haja a necessidade de tomar decisões dentro uma estrutura de governança se discutirá, em algum momento, se estas decisões devem ser isoladas ou colegiadas; se é mais benéfico para a entidade centralizar o poder decisório ou compartilhá-lo com os componentes da pirâmide hierárquica. Estes temas vêm sendo discutidos já há algumas décadas (Jennergren, 1981; Mansfield, 1973; Marsh, 1992), e - recentemente - vem sendo abordados a partir de outros enfoques, associados a modismos e a desempenho (Malone, 1997; Wong, Ormiston, \& Tetlock, 2011).

No fundo, a questão é delegar ou não. Em outras palavras, pode-se dizer que discussão é sobre a tensão que existe entre conferir autonomia e controlar, entre permitir a participação nas decisões e, ao mesmo tempo, limitá-la (Malone, 1997). Waterhouse e Tiessen (1978, p. 68) já haviam abordado esta temática evocando uma "estrutura de autoridade e controle" e distinguindo a autoridade centralizada da descentralizada. Logo percebe-se a íntima conexão entre centralização e autonomia: diz-se que onde há mais centralização há menos autonomia e, por conseguinte, onde há menos centralização há mais autonomia (Horngren, Sundem, Stratton, Teall, \& Gekas, 2006).

No plano pragmático, Hopper (1980) resolveu estudar como os controllers se percebiam, e eram percebidos, tanto nas organizações centralizadas quanto nas descentralizadas. Ele encontrou que nas empresas onde havia um maior nível de descentralização o controller estava mais próximo dos gestores, e que - nesta situação - estes gestores percebiam a informação contábil fornecida pelos controllers como sendo mais pertinente: achavam-na mais adequada às necessidades gerenciais. Deste modo, o estudo de Hopper (1980) sinalizou que a descentralização era um fator capaz de trazer o controller para mais próximo das demandas do negócio e daqueles que o gerenciam. Em outros termos: a descentralização estimulava um perfil de controller mais afinado ao modelo business partner.

Posteriormente, Gul e Chia (1994) descobriram que, em ambientes com alto grau de incerteza, promover a descentralização proporcionava uma melhoria no desempenho dos gestores. A descentralização, portanto, sob certas condições, teria um efeito sobre a performance das pessoas, inclusive do controller.

Dez anos depois, Jermias e Gani (2004) ratificaram as conclusões do estudo de Gul e Chia (1994, p. 187) e afirmaram que "um alto degrau de autonomia é uma resposta apropriada ao aumento da incerteza". É importante entender a ideia subjacente a esta argumentação: em ambientes e/ou situações de grande incerteza (como, por exemplo, no lançamento de um novo produto) o grau de liberdade para tomar decisões (isto é: autonomia) proporciona uma melhor adaptação do negócio ao meio. Por outro 
lado, se o ambiente não oferece tantos riscos (ou seja, em clima de baixa incerteza), a organização tende a reduzir a autonomia dos gestores e centralizar o poder decisório em uma instância única.

Todos estes argumentos e estudos oferecem suficientes indícios para que se suponha que o perfil business partner, reiteradamente destacado pela literatura acadêmica, é o que se adapta mais facilmente a ambientes descentralizados e ao clima de incertezas. Talvez por isso, Jordan, Neves e Rodrigues (2003, p. 431), ao falarem da evolução da profissão do controller, se referem ao novo controller como o responsável pela "animação e coordenação de atividades em estruturas descentralizadas".

Ahid e Augustine (2012) afirmaram que a descentralização e a delegação de autoridade, de fato, resultaram em um incremento de responsabilidade para os controllers. Quando descentralizado o poder, os gestores (delegados) precisam envolver-se mais com o negócio, aprender os detalhes da operação, a fim de saber exatamente sobre o que estão decidindo. Este envolvimento é visto como positivo por Palomino (2013), que o considera uma característica do controller e um fruto da descentralização.

No que diz respeito a este tópico, portanto, foi testada a seguinte hipótese:

H2: Em empresas mais descentralizadas os controllers apresentam mais envolvimento com o negócio e mais autonomia.

\section{MÉTODOS}

A pesquisa foi realizada em parceria com a Associação Nacional dos Executivos de Finanças (ANEFAC), em cuja base de associados constavam 596 controllers. A coleta de dados se deu entre os meses de maio e dezembro de 2015, período em que vigorou a mencionada parceria, tendo em vista que a proposta visava apresentar já no início de 2016 um panorama dos controllers associados àquela entidade. O instrumento de pesquisa utilizado consistiu em um questionário, subdivido em três partes, remetido aos respondentes por e-mail. Neste e-mail indicava-se um link da plataforma virtual gratuita Survey Monkey para que o controller pudesse acessar e responder à pesquisa. Antes, porém, o questionário foi remetido - como piloto - a um controller e dois acadêmicos da área de controladoria, para que se testasse a clareza e a compreensibilidade das questões. Assim, se necessário, a partir das críticas eventualmente recebidas, seria possível aprimorar o instrumento de modo a eliminar dubiedades e/ou imprecisões nas questões.

Além disso, foi elaborada uma breve carta introdutória ao questionário na qual foi feita uma breve explanação da questão-problema que motivou o estudo e se destacou a confidencialidade das respostas. Ainda nesta carta introdutória, foi disponibilizado um e-mail para servir como canal de contato com o pesquisador. Assim, diante de quaisquer dúvidas, os respondentes poderiam contatar o pesquisador a fim de saná-las.

Ao finalizar a coleta de dados, foram obtidos um total de 114 questionários respondidos. Destes, dois respondentes foram descartados da amostra tendo em vista que declararam estar exercendo a função de docentes, e não mais a de controllers. Além disso, um dos respondentes precisou ser excluído do grupo amostral porque respondeu uma única questão (e mesmo assim parcialmente): sua permanência na composição da amostra poderia levar a distorções nos resultados das estatísticas descritivas e consequente interpretação equivocada dos achados. Assim, com 111 questionários validamente respondidos, a taxa de resposta obtida pelo pesquisador foi de $18,62 \%$.

Todas as variáveis foram medidas através de escalas pré-estabelecidas e devidamente validadas. Todas as variáveis originalmente na língua inglesa foram traduzidas para o português através do processo de "back translation". As respostas foram medidas através da escala de Likert de 5 pontos, com exceção da pergunta a respeito da descrição das funções dos controllers. Para que se tenha um entendimento mais claro acerca das medias utilizadas no questionário, foi construído a Tabela 5: 


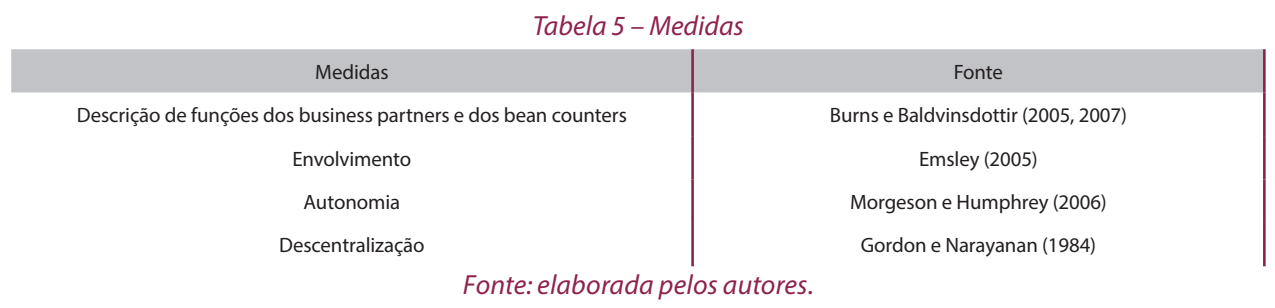

Descrição de funções dos business partners e dos bean counters - No questionário foram disponibilizados cinco campos para que os respondentes elencassem as cinco principais tarefas/atividades que eles realizavam. Deste modo, seguindo uma lógica de codificação, foi possível segregar com mais clareza os perfis que estão sob investigação nesta pesquisa, posto que há atividades mais próximas do perfil bean counters e outras mais próximas do perfil business partner.

Envolvimento - O questionário visou identificar dentro de uma escala Likert de 5 pontos, qual o grau de envolvimento dos controllers com a função contábil, isto é, com as atribuições próprias de um contador tradicional, e com a função de suporte à gestão (em outros termos, o quanto eles assessoram, prestam apoio direto, aos gestores encarregados da estratégia organizacional). A ideia é que o envolvimento mais intenso com a função contábil indica predominância do perfil bean counter, ao passo que envolver-se mais com a função de apoio à gestão revela preponderância do perfil business partner. A média obtida da medida de envolvimento foi de 3,19 e a confiabilidade da escala (Alfa de Cronbach) foi de 0,76.

Autonomia - O questionário buscou medir a autonomia dos controllers, dentro de uma escala Likert de 5 pontos. Essa medida possui três itens: "meu trabalho me permite tomar minhas próprias decisões sobre o cronograma de execução do meu trabalho"; "meu trabalho permite que eu tome muitas decisões por conta própria"; e "meu trabalho fornece autonomia para tomada de decisões". A média obtida da medida de autonomia foi de 3,78 e a confiabilidade da escala (Alfa de Cronbach) foi de 0,88.

Descentralização - Os respondentes também classificaram, dentro de uma escala Likert de 5 pontos, qual o grau de descentralização existente na organização em que atuam no que se refere a algumas decisões específicas. Esta pergunta visou identificar o nível de liberdade, influência e delegação existente na companhia. As decisões foram sobre: desenvolvimento de novos produtos, contratação e demissão de pessoal, investimentos de grande vulto, orçamento, precificação. Seguindo esta lógica, o valor "1" significou "nenhuma autonomia", ao passo que o valor " 5 " indicou "total autonomia". A média obtida da medida de descentralização foi de 2,81 e a confiabilidade da escala (Alfa de Cronbach) foi de 0,86.

O número de funcionários foi adotado como determinante do tamanho (porte) da empresa, através de uma pergunta direta: "Quantos empregados a sua organização possui?".

Para melhor visualização das tarefas e atividades que caracterizam a atuação do controller e possibilitam sua classificação entre bean counters ou business partners, foi utilizada uma word cloud (em português, "nuvem de palavras"). Esta ferramenta, possibilita a visualização das palavras-chave identificadas, de tal forma que o espaço que estes termos ocupam na word cloud gerada é proporcional à quantidade de vezes que eles apareceram nos relatos dos respondentes. A elaboração da word cloud se deu mediante a ferramenta disponibilizada gratuitamente no sítio eletrônico www.worditout.com.

\section{ANÁLISE E DISCUSSÃO DOS RESULTADOS}

Inicialmente, convém apresentar algumas características descritivas do perfil dos controllers da amostra: (a) 77\% dos respondentes se declararam do sexo masculino; (b) a média de idade foi de 43 
anos; (c) 64\% dos respondentes disseram-se pós-graduados, ou seja, têm especialização lato sensu ou fizeram algum curso do tipo Master Business Administration (MBA).

A este perfil prevalente, composto por homens, pós-graduados e de meia idade, acrescente-se um outro dado obtido a partir das respostas colhidas: a média de experiência dos controllers na área de controladoria foi de 6,8 anos. Se esta informação for comparada à média de idade que se apurou, intui-se que, em geral, a atuação dos profissionais da amostra neste ramo deve ter se iniciado após os 35 anos. Feita esta caracterização geral, convém debruçar-se sobre a descrição que os controllers fizeram de seu próprio papel/função no primeiro quesito da parte A. A partir destes relatos, foram identificadas 59 palavras-chave, as quais descrevem não só as tarefas que eles afirmaram desempenhar, mas também atividades e outros elementos presentes em seu cotidiano.

Como exemplos de tarefas, podem-se citar:"cálculos", "cobrança”, "análise" etc.; a título de atividades é possível mencionar:"auditoria", "consultoria", "gestão" etc.; e como outros elementos presentes na realidade profissional dos controllers foram identificados, por exemplo: "arquivos", "dados", "fornecedores" etc. Somando o total de ocorrências destas 59 palavras-chave, foram constatadas 485 referências a estes termos. Isto posto, a word cloud obtida foi a constante na Figura 1, a seguir:

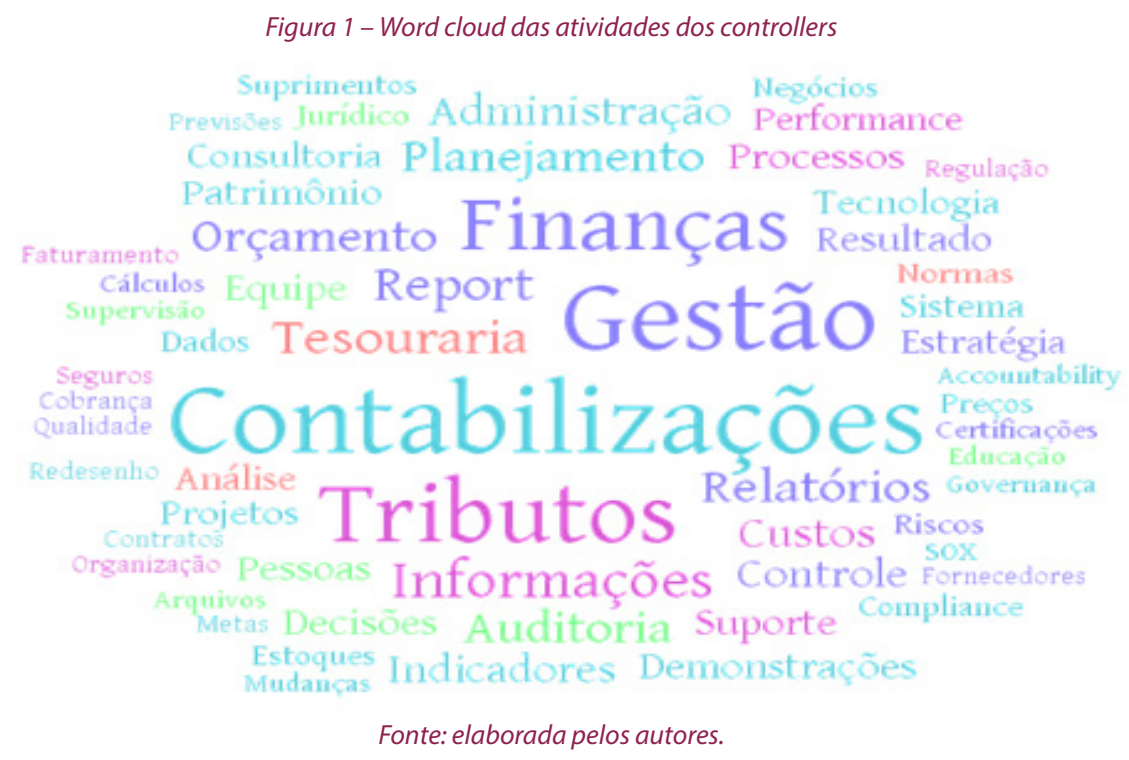

Ao visualizar a word cloud construída, é possível perceber que a palavra "Contabilizações" ocupa a região central do mosaico e se destaca também por apresentar a maior fonte no emaranhado de expressões. Tal observação é pertinente porque denota que a escrituração, o processo de comandar lançamentos contábeis para registrar transações, é bastante presente nas rotinas de muitos controllers, de forma que o envolvimento deles com os negócios empresariais, a sua parceria com as demais áreas da empresa, o seu papel estratégico e as suas atribuições gerenciais não os desobrigaram de realizar (ou supervisionar) este procedimento contábil clássico, que representa a base de qualquer peça da contabilidade e o fundamento de qualquer interpretação sobre os eventos ocorridos na empresa. Em "Contabilizações" estão contidas as rotinas próprias da contabilidade chamada"financeira", o que sugere que o controller está ainda muito atrelado às atribuições do bean counter.

Assim, tendo em vista que "Contabilizações", "Gestão", “Tributos", "Finanças" e "Informações" foram as palavras que sobressaíram na word cloud (cada uma delas com mais de 30 ocorrências, o que indica 
mais de $5 \%$ de representatividade em relação ao total de palavras-chave identificadas), pode-se dizer que tais elementos compõem o cerne da atuação dos controllers no Brasil. Mesmo em seus variados contextos, os controllers parecem unidos por estas atividades que lhes são comuns.

Portanto, considerando as 5 tarefas que cada um dos 111 respondentes foi convidado a elencar, foi possível organizá-las em atividades e distribuí-las da seguinte maneira (Tabela 6):

\begin{tabular}{|c|c|c|c|}
\hline Atividade & Classificação & Frequência & Percentual \\
\hline $\begin{array}{l}\text { 1. Monitoramento fiscal } \\
\text { 2. Controle de custos } \\
\text { 3. Escrituração } \\
\text { 4. Análise de dados/relatórios financeiros } \\
\text { 5. Controle de desempenho gerencial com base nos principais indicadores financeiros } \\
\text { 6. Outras atividades de bean counter }\end{array}$ & Bean counter & $\begin{array}{l}58 \\
39 \\
66 \\
117 \\
68 \\
2\end{array}$ & $\begin{array}{l}10,5 \\
7,0 \\
11,9 \\
21,1 \\
12,3 \\
0,4\end{array}$ \\
\hline $\begin{array}{l}\text { 7. Integração da informação contábil com indicadores de desempenho não financeiros } \\
\qquad \begin{array}{l}\text { 8. Formulação de estratégia } \\
\text { 9. Desenvolvimento de sistemas } \\
\text { 10. Redesenho organizacional } \\
\text { 11. Gestão de mudanças } \\
\text { 12. Outras atividades de business partner }\end{array}\end{array}$ & Business partner & $\begin{array}{l}21 \\
26 \\
13 \\
16 \\
17 \\
6\end{array}$ & $\begin{array}{l}3,8 \\
4,7 \\
2,3 \\
2,9 \\
3,1 \\
1,1\end{array}$ \\
\hline $\begin{array}{l}\text { 13. Atividades burocrático-administrativas } \\
\text { 14. Atividades não relacionadas à contabilidade/ controladoria } \\
\begin{array}{l}\text { 14. Outras atividades } \\
\text { 16. Não responderam }\end{array}\end{array}$ & Não classificáveis & $\begin{array}{l}29 \\
10 \\
26 \\
41\end{array}$ & $\begin{array}{l}5,2 \\
1,8 \\
4,6 \\
7,3\end{array}$ \\
\hline \multicolumn{2}{|l|}{ Total } & 555 & 100,0 \\
\hline
\end{tabular}

Alguns respondentes, destoando do que fora solicitado, não fizeram a indicação de cinco tarefas: optaram por relacionar três ou quatro - razão pela qual houve 41 ocorrências de ausência de resposta. Além disso, como muitos respondentes relacionaram atividades de ambos os perfis (tendo alguns inclusive optado por indicar menos de cinco atividades), o que se obteve, por fim, foi um perfil predominante (estabelecendo como critério de predominância que quem indicasse executar duas ou mais atividades de business partner seria classificado como tal). O resultado deste procedimento foi o constante na Tabela 7:

Tabela 7 - Distribuição das atividades dos controllers

\begin{tabular}{|c|c|c|c|c|}
\hline Perfil & Frequência & Percentual & \% Válido & \% Cumulativo \\
\hline Bean counters & 76 & 68,5 & 74,5 & 74,5 \\
Business partners & 26 & 23,4 & 25,5 & 100,0 \\
\hline Total & 102 & 91,9 & 100,0 & - \\
\hline Sem classificação & 9 & 8,1 & - & - \\
\hline Total & 111 & 100,0 & - & - \\
\hline
\end{tabular}

Fonte: elaborada pelos autores.

Os respondentes que não foram classificados como sendo bean counter ou business partners são aqueles cujas atividades foram marcadas pela predominância dos itens 13, 14 e 15 (vide Tabela 6). Entre os demais respondentes, porém, como se pode observar, o perfil predominante apurado foi o do bean counter.

Palomino (2013) endossa o entendimento segundo o qual os controllers apresentam uma variabilidade de funções e atividades, a depender do tamanho e da estrutura específica da empresa em que atuam. A argumentação que embasa esta ideia alude ao fato de que o porte e o modo como a empresa 
está desenhada exige do controller diferentes competências e posturas e, em consequência, isto se reflete em suas funções e atividades. Assim, em teoria, o tamanho da organização desempenharia um papel significativo no envolvimento do controller com o negócio e na sua autonomia dentro da organização.

Entretanto, o que se constatou a partir dos dados da presente pesquisa divergiu deste entendimento. Em primeiro lugar, o tamanho médio das companhias foi de 2.432 funcionários. Esta média (livre do viés dos outliers) não é compatível com a realidade de empresas pequenas, e aponta para o contexto das organizações de grande porte: enquanto nas primeiras o controle pode ser (e muitas vezes é) exercido por um funcionário de confiança ou pelo próprio empresário, nas últimas, a figura do controller desponta para satisfazer a necessidade de profissionalizar e instrumentalizar a gestão de uma entidade que, em razão de sua complexidade, já não admite mais amadorismos.

Ademais, à revelia da argumentação de alguns autores, e utilizando a técnica da regressão linear, percebeu-se que não houve relação significante entre o tamanho da empresa e o envolvimento do controller no negócio $(\beta=-, 12, t=-1,14, p=, 26)$.

Uma possível explicação para isto pode residir no fato de que nas organizações menores o controller tem condições de conhecer o negócio com mais proximidade e inteireza. Isto faz com que ele esteja pessoal e integralmente envolvido. Ao passo que em grandes organizações, ante um rol de atribuições tão extenso e cercado por tantas demandas (muitas delas burocráticas e/ou legais), o controller não tem condições, oportunidade e tempo de se envolver.

A regressão linear também apontou que a relação entre o tamanho da companhia e a autonomia do controller não foi significante $(\beta=-, 07, t=-, 63, p=, 53)$. Estes números refletem a lógica segundo a qual, o fato de a empresa ser de maior porte não implica, necessariamente, num maior grau de autonomia para o controller. Da mesma forma, também não se pode assegurar que - em empresas menores - ele tem menos autonomia. Destaca-se que nas empresas de maior porte o controller também é um dos "itens" passíveis de controle e, por isso, de fato, sua autonomia é limitada: em contextos onde se fala de governança não há espaço para "amplos poderes". Logo, mesmo não permitindo a associação entre porte e autonomia ou envolvimento, os dados trazem uma outra vertente lógica de argumentação igualmente válida e consistente com a realidade.

Portanto, hipótese $\mathrm{H} 1$ foi rejeitada, o que significa que os controllers de empresas de maior porte (isto é, com maior número de funcionários) não apresentam maior grau de autonomia ou envolvimento com o negócio.

Em relação a hipótese $\mathrm{H} 2$, identificou-se que a descentralização está positivamente associada ao envolvimento, o que significa que quanto mais descentralizada a empresa, maior o nível de envolvimento do controller no negócio $(\beta=, 21, t=2,02, p<, 05)^{4}$.

Com base neste resultado, parece que a estrutura descentralizada impele o controller a estar mais próximo do negócio - talvez para que ele não perca o controle e possa exercer sua função em consonância com as outras "partes" da engrenagem-empresa. Monteiro (2014, p. 32) comenta: "Descentralização está associada com um Sistema de Controle Gerencial com características de agregação e integração". Diante de tal afirmação, e tendo em conta os achados da presente pesquisa a este respeito, surge uma provocação: se nas estruturas descentralizadas há, como insinua Monteiro (2014), mais proximidade e interação entre os personagens que exercem o poder, então pode haver - entre eles - troca de experi- 
ências, compartilhamento de dificuldades, comunicação de saberes etc. O envolvimento do controller no negócio, portanto, é somente o reflexo deste movimento.

Ahid e Augustine (2012) indicam que o incremento nas atividades do controller é um dos frutos da descentralização das organizações. O presente estudo prossegue nesta mesma linha de raciocínio, mas avança ao apontar que o envolvimento do controller nestas atividades que lhe são atribuídas também é fruto da descentralização.

Os achados da presente pesquisa avançam, ainda, em relação ao estudo de Wong et al. (2011), tendo em vista que tais autores examinaram os efeitos da descentralização, fazendo relação com o que chamaram de "complexidade interativa" mas sem descer esta complexidade ao nível da especificação de tarefas e prescindindo do envolvimento dos controllers na execução delas.

Byrne (2010) faz menção ao envolvimento dos controllers com o negócio mas sem associar isto, em momento algum, ao fator descentralização. Desta forma, a relação entre estes dois elementos, aqui encontrada e comprovada, contribui para aprofundar o conhecimento dos "antecedentes, características e consequências associados ao papel dos controllers", a que Byrne (2010) fez referência no título de sua pesquisa.

Os achados decorrentes do questionário que foi aplicado aos 111 respondentes desta pesquisa sugerem, a este respeito, que - nas organizações onde o poder decisório é descentralizado - os controllers envolvem-se mais. Neste sentido, a descentralização incrementa a responsabilidade destes profissionais sobre as tarefas e atividades que Ihes foram confiadas, e os impele a envolver-se mais com tudo quanto realizam e com a dinâmica da própria entidade em que atuam.

Foi identificada ainda, a existência de uma relação significante entre descentralização e autonomia $(\beta=, 35, t=3,59, p<, 01)^{5}$. A lógica subjacente à descentralização é a de compartilhamento do poder de mando. Logo, é natural que esta pulverização do poder incremente a autonomia dos profissionais que de alguma forma o exercem.

Convém notar que o binômio autonomia-controle é, por natureza, paradoxal: onde o controle é mais forte há menos autonomia, e onde o controle é menos rigoroso há mais espaço para posições e decisões autônomas. Isto posto, é compreensível que sendo o controle menor, porque fragmentado com a descentralização, haja uma maior dose de autonomia. Nesta perspectiva, por exemplo, situa-se o estudo de Sbors, Schafer e Gasparetto (2017), segundo os quais a existência de divisões descentralizadas permite que haja mais autonomia.

Mas esta autonomia, alertaram Ferreira e Angotti (2016), precisa estar integrada ao sistema de controle gerencial como um todo para que não fique incongruente em relação aos objetivos da companhia. Portanto, a discussão sobre descentralização e autonomia, ao perpassar dimensões estratégicas e envolver diretamente a área de controle, alça os profissionais de controladoria a um papel mais amplo e elevado, de mais colaboração com o negócio. Com a descentralização quem nunca teve poder pode passar a tê-lo. E ao receber, por delegação, uma fatia de poder, se lhes exige simultaneamente que suas decisões (autônomas) estejam alinhadas aos interesses da organização e sejam frutuosas para a mesma.

Os achados da presente pesquisa dão conta de uma dimensão que não vem sendo suficientemente tratada: a existência de um gatilho (a descentralização) para a autonomia dos controllers. $O$ estudo de Kalbers e Cenker (2008), por exemplo, assinala a existência de uma associação entre a autonomia e a

5 Foram realizados todos os testes de pressupostos do modelo de regressão: teste de normalidade dos resíduos, ausência de autocorrelação dos resíduos, homocedasticidade e linearidade. Todos os pressupostos foram adequados. O teste de Durbin-Watson (teste para autocorrelação) foi de 2,13 , esse valor significa que os resíduos não estäo correlacionados. Portanto, isso indica que a premissa foi atendida. 
performance dos contadores certificados, mas não elucida os elementos catalisadores desta autonomia e ignora a descentralização como sua mola propulsora.

Enfim, os achados levam à aceitação da hipótese H2. Em outras palavras: a descentralização em uma organização está associada positivamente à autonomia dos controllers e também guarda relação positiva com o envolvimento destes no negócio.

\section{CONCLUSÃO}

Nosso estudo possui três objetivos: identificar as principais atividades exercidas pelos controllers, discernir qual o seu perfil predominante (considerando as variantes que a literatura aponta, notadamente bean counters e business partners), e entender como o tamanho e grau de descentralização das organizações se relacionam com a autonomia e o envolvimento destes controllers com os negócios da empresa em que trabalham.

Como resultado desta investigação, entre as principais atividades executadas pelos controllers, destacaram-se: a análise de dados e relatórios financeiros, o controle de desempenho gerencial com base nos principais indicadores financeiros, a escrituração, e o monitoramento fiscal. Como complemento deste achado, e corroborando-o, a word cloud construída demonstrou que as palavras "Contabilizações", "Gestão", "Tributos" e "Finanças" foram as que sobressaíram na descrição que os respondentes fizeram de suas próprias tarefas.

A averiguação do perfil dos controllers da amostra revelou uma predominância do perfil bean counter: $74,5 \%$ dos respondentes foram assim classificados enquanto apenas $25,5 \%$ foram associados ao perfil business partner. Corroborando esta predominância, tem-se que as tarefas e atividades executadas e apontadas pelos respondentes mostram-se consistentes com a descrição de afazeres que a literatura acadêmica atribui aos bean counters.

A presente pesquisa também analisou se o"Tamanho da Organização"e o grau de "Descentralização" do poder decisório estariam associados com o envolvimento e a autonomia do controller. A hipótese $\mathrm{H} 1$ (relação tamanho da empresa versus envolvimento e autonomia) foi rejeitada. A hipótese $\mathrm{H} 2$ (relação descentralização versus envolvimento e autonomia), se mostrou significante e, por isso, foi aceita.

Estes achados contribuem com o entendimento sobre os reflexos que determinados componentes organizacionais (como tamanho e descentralização) geram sobre certas dimensões da atuação dos controllers. Compreender a existência/inexistência destas relações oferece um pano de fundo e um subsídio para que estudos posteriores possam explicar por que alguns aspectos internos e externos à organização que podem levar à consolidação/redefinição de perfis profissionais e atividades laborais.

Não é demais salientar que este resultado, bem como todos os demais achados elencados nesta conclusão, dizem respeito apenas à amostra pesquisada - a qual, embora represente adequadamente a população de controllers, não reflete, evidentemente, todas as possibilidades e características destes profissionais. Contudo, o que aqui foi exposto, inobstante as limitações já apresentadas, traz indícios que reforçam e lastreiam o debate sobre a transição de perfil que os controllers têm vivenciado.

Esta pesquisa, como já referido no item que tratou da metodologia, teve uma abordagem quantitativa. Sugere-se que outros estudos abordem a problemática relativa ao perfil dos controllers sob uma ótica qualitativa, quiçá realizando entrevistas com ele a fim de entender melhor certos aspectos caracterizadores de seu perfil. Além disso, pode-se estudar o impacto de fatores como o"setor empresarial" em que o controller trabalha e a "cultura da organização", na definição ou consolidação de perfil deste profissional. 
Este estudo contribuiu para elucidar a atuação dos controllers, mediante uma descrição de suas tarefas e atividades, incrementando a discussão sobre a mudança de perfil dos controllers: a transição de bean counters para business partners, verificada em outras partes do mundo, não se mostrou consistente com o perfil da amostra aqui utilizada (de acordo com os dados obtidos, para cada controller do tipo business partner há cerca de três bean counters). Este achado, por sua vez, também representa uma contribuição relevante para o debate sobre quais são, exatamente, os direcionadores desta mudança de perfil.

\section{REFERÊNCIAS}

Abernethy, M. A., \& Brownell, P. (1999). The role of budgets in organizations facing strategic change: an exploratory study. Accounting, Organizations and Society, 24(3), 189-204. DOI: https://doi.org/10.1016/ S0361-3682(98)00059-2

Ahid, M., \& Augustine, A. (2012). The roles and responsibilities of management accountants in the era of globalization. Global Journal of Management and Business Research, 12(15), $42-53$.

Ahlgren, L., Engel, L. C. (2011). Lifelong learning through SMEs: exploring workplace learning in the UK. Journal of Workplace Learning, 23(5), 331-348. DOI: https://doi.org/10.1108/13665621111141920

Ahrens, T., \& Chapman, C. S. (2000). Occupational identity of management accountants in Britain and Germany. European Accounting Review, 9(4), 477-498. DOl: https://doi.org/10.1080/09638180020024070

Brewer, P. C. (2008). Redefining management accounting: promoting the four pillars of our profession. Strategic Finance, 89(9), 35-43.

Burns, J., \& Baldvinsdottir, G. (2005). An institutional perspective of accountants' new roles-the interplay of contradictions and praxis. European Accounting Review, 14(4), 725-757. DOI: https://doi. org/10.1080/09638180500194171.

Burns, J., \& Baldvinsdottir, G. (2007). The changing role of management accountants. In T. Hopper, D. Northcott, \& R. Scapens (Orgs.). Issues in management accounting (3rd. ed.) (pp. 117-132). Harlow: Pearson Education.

Burns, J., \& Scapens, R. (2000, November). The changing nature of management accounting and the emergence of "hybrid" accountants. IFAC Press Center Articles Library. Retrieved on 2015, 31 March, from http://www.ifac.org/Library/SpeechArticle.tmpl?NID=97542618861156.

Byrne, S. (2010). Antecedents, characteristics, and consequences associated with the roles of management accountants, and assisting managers in their roles. Doctoral Thesis in Philosophy, Dublin City University, Dublin.

Byrne, S., \& Pierce, B. (2007). Towards a more comprehensive understanding of the roles of management accountants. European Accounting Review, 16(3), 469-498.DOI:https://doi.org/10.1080/09638180701507114.

Calijuri, M. S. S. (2004). Controller: o perfil atual e a necessidade do mercado de trabalho. Revista Brasileira de Contabilidade, 33(150), 38-53.

Calijuri, M. S. S., Santos, N. M. B. F., \& Santos, R. F. dos. (2005). Perfil do controller no contexto organizacional atual brasileiro. Anais do Congresso Brasileiro de Custos, Florianópolis, SC, 12.

Cardoso, R. L., Mendonça Neto, O. R., \& Oyadomari, J. C. (2010). Os estudos internacionais de competências e os conhecimentos, habilidades e atitudes do contador gerencial brasileiro: análises e reflexões. Brazilian Business Review, 7(3), 91-113.

Chartered Global Management Accountants. (2014). Global management accounting principles. London: CGMA. Retrieved on 2015, 29 March, from http://www.cgma.org/principles. 
Chen, H., \& Taylor, R. D. (2012). The impact of lean design practices on an organization's radical innovation capability: an empirical study. Proceedings of Portland International Conference on Management of Engineering \& Technology (pp. 1917-1925), Vancouver, 12.

Dayanti, N., \& Prihatiningtias, Y.W. Corporate social responsibility disclosure and firm financial performance: the case of mining and natural resources industry in Indonesia. Jurnal IImiah Mahasiswa FEB, 1(2), 2013.

De Loo, I., Verstegen, B., Swagerman, D. (2011). Understanding the roles of management accountants. European Business Review, 23(3), 287-313. DOI: https://doi.org/10.1108/09555341111130263.

Duque, C. (2011). O perfil profissional do controller e as funções de controladoria: um estudo da atual necessidade do mercado de trabalho. 2011. Dissertação de Mestrado em Ciências Contábeis, Universidade Federal de Pernambuco, Recife.

Emsley, D. (2005). Restructuring the management accounting function: a note on the effect of role involvement on innovativeness. Management Accounting Research, 16(2), 157-177. DOI: https://doi. org/10.1016/j.mar.2005.02.002.

Ferrari, M. J., Cunha, L. C., Lunkes, R. J., \& Borgert, A. (2013). O perfil do controller sob a ótica do mercado de trabalho nacional. Revista de Informação Contábil, 7(3), 25-50.

Ferreira, R. M., \& Angotti, M. (2016). Os benefícios do conceito BSC para coordenação estratégica na descentralização: estudo de caso de uma empresa de médio porte de energia alternativa. Revista de Administração \& Ciências Contábeis, 3(1).

Friedman, A. L., \& Lyne, S. R. The bean counter stereotype: towards a general model of stereotype generation. Critical Perspectives on Accounting, 12(4), 423-451. DOl: https://doi.org/10.1006/cpac.2000.0451.

Gibson, D. A. (2002). On-property hotel financial controllers: a discourse analysis approach to characterizing behavioural roles. International Journal of Hospitality Management, 21(1), 5-23. DOI: https://doi. org/10.1016/s0278-4319(01)00018-4

Gordon, L. A., \& Narayanan, V. K. (1984). Management accounting systems, perceived environmental uncertainty and organization structure: an empirical investigation. Accounting, organizations and society, 9(1), 33-47. DOI: https://doi.org/10.1016/0361-3682(84)90028-x.

Granlund, M., \& Lukka, K. (1998). Towards increasing business orientation: finish management accountants in a changing cultural context. Management Accounting Research, 9(2), 185-211. DOl: https://doi. org/10.1006/mare.1998.0076.

Guimarães, M. do C. L. (2014). O debate sobre a descentralização de políticas públicas: um balanço bibliográfico. Organizações \& Sociedade, 9(23), 2014. DOI: https://doi.org/10.1590/s1984-92302002000100003.

Gul, F. A., \& Chia, Y. M. (1994). The effects of management accounting systems, perceived environmental uncertainty and decentralization on managerial performance: a test of three-way interaction. Accounting, Organizations and Society, 19(4), 413-426. DOI: https://doi.org/10.1016/0361-3682(94)90005-1.

Hamdan, A. M. M. (2011). The impact of company size, debt contracts, and type of sector on the level of accounting conservatism: an empirical study from Bahrain. International Journal of Business and Management, 6(7), 134-146. DOI: https://doi.org/10.5539/ijbm.v6n7p134.

Holtzman, Y. (2004). The transformation of the accounting profession in the United States: from information processing to strategic business advising. Journal of Management Development, 23(10), 949-961. DOI: https://doi.org/10.1108/02621710410566856.

Hopper, T. (1980). Role conflicts of management accountants and their position within organisation structures. Accounting, Organizations and Society, 5(4), 401-411. DOI: https://doi.org/10.1016/03613682(80)90039-2.

Horngren, C. T., Sundem, G. L., Stratton, W. O., Teall, H. D., \& Gekas, G. A. (2006). Management accounting. (5th ed.). Harlow: Pearson Education.

Institute of Chartered Accountants in England and Wales. (2004). Sustainability: the role of accountants: sustainable business initiative. London: ICAEW. 
International Federation of Accountants. (2005, August). International guidance document on environmental management accounting. New York, IFAC.

Järvenpää, M. (2007). Making business partners: a case study on how management accounting culture was changed. European Accounting Review, 16(1), 99-142. DOl: https://doi.org/10.1080/09638180701265903.

Jennergren, L. P. (1981). Decentralization in organizations. In: P. C. Nystrom, \&W. H. Starbuck (Orgs.). Handbook of organizational design (v. 2, pp. 39-59). New York: Oxford University Press.

Jermias, J., \& Gani, L. (2004). Integrating business strategy, organizational configurations and management accounting systems with business unit effectiveness: a fitness landscape approach. Management Accounting Research, 15(2), 179-200. DOI: https://doi.org/10.1016/j.mar.2004.03.002.

Jordan, H., Neves, J. C. das, \& Rodrigues, J. A. (2003). O controlo de gestão - ao serviço da estratégia e dos gestores. (5a. ed.). Lisboa: Áreas.

Laforet, S. (2008). Size, strategic, and market orientation affects on innovation. Journal of Business Research, 61(7), 753-764. DOI: https://doi.org/10.1016/j.jbusres.2007.08.002.

Kalbers, L. P., \& Cenker, W. J. (2008). The impact of exercised responsibility, experience, autonomy, and role ambiguity on job performance in public accounting. Journal of Managerial Issues, 2(3), 327-347.

Lambert, C., \& Sponem, S. (2012). Roles, authority and involvement of the management accounting function: a multiple case-study perspective. European Accounting Review, 21(3), 565-589. DOI: https://doi.org/10.1 080/09638180.2011.629415.

Lunkes, R. J., Gasparetto, V., \& Schnorrenberger, D. (2010). Um estudo sobre as funções da controladoria. Revista de Contabilidade e Organizações, 4(10), 106-126. DOl: https://doi.org/10.11606/rco.v4i10.34779.

Malone, T. W. (1997). Is empowerment just a fad? Control, decision making, and IT. Sloan Management Review, 38(2), 22-35.

Mansfield, R. (1973). Bureaucracy and centralization: an examination of organizational structure. Administrative Science Quarterly, 18(4), 477-488. DOI: https://doi.org/10.2307/2392200.

Marsh, R. M. (1992). A research note: centralization of decision-making in Japanese factories. Organization Studies, 13(2), 261-274. DOI: https://doi.org/10.1177/017084069201300206.

Mistry, V., Sharma, U., \& Low, M. (2014). Management accountants' perception of their role in accounting for sustainable development: an exploratory study. Pacific Accounting Review, 26(1-2), 112-133. DOI: https:// doi.org/10.1108/par-06-2013-0052.

Monteiro, J. A. de M. (2014). Influência da implementação das normas internacionais de contabilidade e da contabilidade regulatória sobre o sistema de contabilidade gerencial das companhias de energia elétrica brasileiras. Dissertação de Mestrado em Ciências Contábeis, Universidade Federal de Pernambuco, Recife.

Morgeson, F. P., \& Humphrey, S. E. (2006). The Work Design Questionnaire (WDQ): developing and validating a comprehensive measure for assessing job design and the nature of work. Journal of Applied Psychology, 91(6), 1321. DOI: https://doi.org/10.1037/0021-9010.91.6.1321.

Motta, F. C. P., \& Bresser-Pereira, L. C. (2004). Introdução à organização burocrática. São Paulo:Thomson.

Nogueira, V., \& Fari, M. A. (2007). Perfil do profissional contábil: relações entre formação e atuação no mercado de trabalho. Perspectivas Contemporâneas, 2(1), 117-131.

Oro, I. M., Dittadi, J. R., Carpes, A. M. D. S., \& Benoit, A. D. (2009). O perfil do profissional de controladoria sob a óptica do mercado de trabalho brasileiro. Pensar Contábil, 11(44), 5-15.

Palomino, M. N. (2013). Conflito, ambiguidade de função e satisfação no trabalho: percepções dos controllers brasileiros. Tese de Doutorado em Ciências Contábeis, Universidade de São Paulo, São Paulo. DOI: https:// doi.org/10.11606/d.12.2013.tde-08112013-184722 
Pierce, Bernard, \& O'dea, T. (2003). Management accounting information and the needs of managers: perceptions of managers and accountants compared. The British Accounting Review, 35(3), 257-290. DOI: https://doi.org/10.1016/s0890-8389(03)00029-5

Pinto, J. R. A. (1997). Descentralização e controle gerencial: estudo de cinco casos brasileiros. Dissertação de Mestrado em Administração, Universidade Federal do Rio de Janeiro, Rio de Janeiro.

Rahman, S., \& Ahmed, J. U. (2012). An evaluation of the changing role of management accountants in recent years. Indus Journal of Management \& Social Science (IJMSS), 6(1), 18-30.

Sathe, V. (1984). The controller's role in management. Organizational Dynamics, 11(3), 31-48. DOI: https:// doi.org/10.1016/0090-2616(83)90004-9

Sbors, R., Schafer, J. D., \& Gasparetto, V. (2017). Divisionalização e Contabilidade por Responsabilidade em Operações Comerciais e de Serviços. Revista Gestão \& Tecnologia, 17(1), 232-257.DOI: https://doi. org/10.20397/2177-6652/2017.v17i1.1002

Schnorrenberger, D., Ribeiro, L. M. S., Lunkes, R. J., \& Gasparetto, V. (2007). Perfil do controller em empresas de médio e grande porte da grande Florianópolis. Anais do Congresso Brasileiro de Custos, João Pessoa, 14. DOI: https://doi.org/10.16930/2237-7662/rccc.v7n20p57-70

Siegel, G. (2000). The image of corporate accountants. Strategic Finance, 82(2), 71-72.

Siegel, G., \& Sorensen, J. E. (1999). Counting more, counting less: the 1999 practice analysis of management accounting. Montvale, NJ: Institute of Management Accountants.

Singer, P. (2004). Desenvolvimento capitalista e desenvolvimento solidário. Estudos Avançados, 18(51), 7-22. DOI: https://doi.org/10.1590/s0103-40142004000200001

Sunarni, C. W. (2013). Management accounting practices and the role of management accountant: evidence from manufacturing companies throughout Yogyakarta, Indonesia. Review of Integrative Business \& Economics Research, 2(2), 616-626.

Vaivio, J., \& Kokko, T. (2006). Counting big: re-examining the concept of the bean counter controller. Liiketaloudellinen Aikakauskirja, 55(1), 49-74.

Verstegen, B. H. J., De Loo, I., Mol, P., Slagter, K, \& Geerkens, H. (2007). Classifying controllers by activities: an exploratory study. Journal of Applied Management Accounting Research, 5(2), 9-32.

Vieira, P. R. (2012). Em busca de uma teoria de descentralização. Revista de Administração Pública, 46(5), 1409-1425. DOI: https://doi.org/10.1590/s0034-76122012000500011

Waterhouse, J. H., \& Tiessen, P. (1978). A contingency framework for management accounting systems research. Accounting, Organizations and Society, 3(1), 65-76. DOI: https://doi.org/10.1016/03613682(78)90007-7

Wong, E. M., Ormiston, M. E., \& Tetlock, P.E. (2011). The effects of top management team integrative complexity and decentralized decision making on corporate social performance. Academy of Management Journal, 54(6), 1207-1228. DOI: https://doi.org/10.5465/amj.2008.0762

Youssef, M. A. (2012). Management accounting change in developing countries. Journal of Accounting \& Marketing, 3(1). DOI: https://doi.org/10.4172/2168-9601.1000e123 